Annuaire du Collège de France 2011-2012

\title{
Étude de la création littéraire en langue anglaise,
} 2002-2008

\section{Michael Edwards}

\section{(2) OpenEdition \\ Journals}

Édition électronique

URL : https://journals.openedition.org/annuaire-cdf/1070

DOI : 10.4000/annuaire-cdf.1070

ISBN : 978-2-7226-0325-7

ISSN : 2109-9227

Éditeur

Collège de France

Édition imprimée

Date de publication : 1 avril 2013

Pagination : 787-788

ISBN : 978-2-7226-0198-7

ISSN : 0069-5580

\section{Référence électronique}

Michael Edwards, «Étude de la création littéraire en langue anglaise, 2002-2008 », L'annuaire du

Collège de France [En ligne], 112 | 2013, mis en ligne le 22 novembre 2013, consulté le 22 août 2022.

URL : http://journals.openedition.org/annuaire-cdf/1070 ; DOI : https://doi.org/10.4000/annuaire-cdf. 1070 


\section{COLLOQUeS}

- «Ordering Legal Pluralism», key note speech in The European China Law Studies Association, Annual General Conference, Law and Justice: China's practices in a Global Context, Fondation des sciences politiques, Paris, 28-29 septembre 2011.

- «L'harmonisation des règles de droit », table ronde franco-chinoise, Fondation Victor Segalen, Paris, 29-30 septembre 2011.

- «Sécurité et dangerosité », Les pièges de la sécurité, Académie des sciences morales et politiques, 17 octobre 2011, (cf. Rev. française de droit administratif, 2011, précité).

- «Les forces imaginantes du droit», débat avec Peter Kemp, 30 e Symposium of Eco-ethica, Le nouvel ordre du monde, Paris, 24 octobre 2011 ; paru dans Eco-ethica, vol. 2, 2012.

- «Conclusions », Droit à la vérité et justice de transition dans les pays du cône sud, 1-2 décembre 2011, Faculté de droit de l'Université de Saô Paulo (Brésil).

- «L'humanisme juridique et la diplomatie culturelle », Institut français et Collège de France, Paris, 12-13 décembre 2011.

- «Formes, normes et dogmes », La vie des formes, Colloque de rentrée du Collège de France, 14 décembre 2011 (publié dans Changeux J.-P., La vie des formes, Odile Jacob, 2012) ; également La Science et les normes : entre éthique et droit, Quatrième Université européenne d'été, IHEST, 27 août 2012 (à paraître).

- «Le procureur européen et les règles pénales modèles », discours inaugural, Un projet pour le parquet européen ?, Luxembourg, 13-15 juin 2012, à paraître.

- «Humaniser la mondialisation : une utopie dynamique et réaliste », Cabé Ch. (dir.), Atlas des utopies, Le Monde, hors-série, 2012.

\section{DISTINCTIONS}

- Docteur honoris causa de l'Institut national des sciences pénales (INACIPE), Mexico, 2012.

- «Prominent Woman in International Law Award», American Society of International Law, Washington D.C., 2012.

- Prix International Silvia Sandano, Rome, 2012.

- «Promotion Mireille Delmas-Marty », École du barreau de Poitiers, 2011-2012.

\section{Michael EDWARDS}

\section{Étude de la création littéraire en langue anglaise, 2002-2008}

\section{Publications}

Edwards M., «John Constable regarde, distrait » (poème), Christian Gardair, Ciel( $s$ ), Libourne, LIS 33, 2011, p. 18-20.

Edwards M., «Poésie et vérité », XVII-XVIII, n 68, 2012, p. 173-185.

Edwards M., «Le jeu du latin dans la poésie anglaise », Sans le latin, éd. Suzzoni, Aupetit, Fayard, Mille et une nuits, 2012, p. 123-138. 
Edwards M., «At the Brasserie Lipp, $\S 5$ » (poème), Poetry Salzburg Review, $\mathrm{n}^{\circ}$ 21, printemps 2012, p. 80-81.

Edwards M., « Hopkins autrement dit », Nunc, $\mathrm{n}^{\circ}$ 27, juin 2012, p. 92-96.

Edwards M., «Gravité de la gravure. Sur Pascale Hémery », Conférence, $\mathrm{n}^{\circ} 34$, printemps 2012, p. 159-176.

\section{Colloques, CONFÉRENCES, ENTRETIENS}

«Shakespeare et la douceur», La Douceur dans la pensée moderne, Université ParisSorbonne (Paris IV), 15 décembre 2011.

Entretien à Canal-Académie (Axël Maugey), 3 janvier 2012.

«Les Arts du visible et la 'nouvelle terre' », Collège des Bernardins, 26 janvier 2012.

«La lecture de la poésie », Salle des fêtes de la mairie d'Avignon, 31 janvier 2012.

«Shakespeare en France », avec Pierre Brunel, Canal-Académie, 26 février 2012.

«Les Psaumes comme poésie de la foi », Redécouvrir les Psaumes, Faculté Libre de Théologie Évangélique, Vaux-sur-Seine, 24 mars 2012.

«Qu'est-ce que l'émerveillement?», Les Nouveaux Chemins de la Connaissance (Adèle Van Reeth), France Culture, 26 mars 2012.

Table ronde, « Geoffrey Hill », École normale supérieure, 13 avril 2012.

«La poésie, langue vivante étrangère », D’autres langues que la mienne, Collège de France, 11 mai 2012.

«Shakespeare : les sources de la guerre, les ressources de la paix », Les arts de la paix dans une Europe en guerre, Collège de France, 6 juin 2012.

«The Transcendence of Things Seen », Hardy poète, Université d'Artois, 8 juin 2012.

«Le Beau», conversation avec Shu Kewen filmée par Volker Schlöndorf, le Louvre, $1^{\text {er }}$ juillet 2012 .

«Une approche transculturelle poétique du patrimoine de l'Art », 3e Forum transculturel euro-chinois de haut niveau, auditorium du Louvre, 4 juillet 2012.

\section{DIFFUSION DES IDÉES}

«L'Art peut-il sauver l'amour?», table ronde, Forum d'Action Modernités, Théâtre du Rond-Point, Paris, 12 septembre 2011.

«L'Anglo-Normandie », Ancienne Abbaye de Grestain, 25 septembre 2011.

$\mathrm{M}^{\mathrm{me}}$ Anne FAGOT-LARGEAULT, membre de l'Institut

(Académie des sciences)

Philosophie des sciences biologiques et médicales, 2001-2009

TrAVAUX PUBLIÉS EN 2011

\section{Livre}

Fagot-Largeault A. (dir.), Dupont J.-C.K. \& Guillin V. (coord.), L'émergence de la médecine scientifique, Paris, Éditions Matériologiques, Coll. «Sciences \& Philosophie », 2011. 